\title{
Histoplasmosis pulmonar: presentación de un caso
}

\author{
MANUELA PÉREZ M.*, PATRICIA BITAR H.**, \\ J. ANTONIO VALENZUELA D.*** y PATRICIO RODRÍGUEZ D.****
}

\section{Pulmonary histoplasmosis: a case report}

Histoplasmosis is the most common of geographic mycoses; in Chile, infection caused by this dysmorphic fungus has been reported only sporadically among persons who have traveled to endemic areas. We report a healthy patient case who consulted 6 months after her trip, with chest pain as single symptom. Surgery and histological study of the pulmonary nodule showed that it was a pulmonary histoplasmosis case.

Key words: Pulmonary nodule, Mycosis, Histoplasmosis.

\section{Resumen}

La histoplasmosis corresponde a la micosis geográfica más frecuente; en nuestro medio, la infección por este hongo dismórfico sólo ha sido reportada en forma esporádica entre quienes han viajado a zonas endémicas. Presentamos el caso de una paciente sana que consultó 6 meses después de su viaje, con dolor torácico como única sintomatología. La cirugía y el estudio histológico del nódulo pulmonar resecado mostraron que se trataba de un caso de histoplasmosis pulmonar.

Palabras clave: Nódulo pulmonar, Micosis, Histoplasmosis.

\section{Introducción}

La histoplasmosis corresponde a la infección por el hongo Histoplasma capsulatum, esporádica en nuestro medio debido a las desfavorables condiciones climáticas para su desarrollo, cuya incidencia ha ido en aumento en los últimos años debido al sostenido incremento de los viajes transoceánicos de la población general.

Presentamos el caso de una paciente joven cuya única sintomatología fue un leve dolor torácico y en la cual el antecedente de viaje fue fundamental para la sospecha diagnóstica.

\section{Caso clínico}

Paciente de sexo femenino de 20 años, estudiante de $1^{\text {er }}$ año de psicología, sin antecedentes patológicos de interés. Consulta en forma ambulatoria a mediados de julio por un cuadro de varias semanas de evolución de moderado dolor torácico con tope inspiratorio, que describe como no progresivo, bilateral y sin otros síntomas asociados. La exploración física general no arrojó hallazgos relevantes.

La radiografía (Rx) de tórax contemporánea (Figura 1) demostró la presencia de un nódulo de $12 \mathrm{~mm}$ sobreproyectado al lóbulo superior derecho, de base pleural, sin calcificaciones; no se visualizaron otras alteraciones en el parénquima pulmonar. Se contó con Rx previa obtenida 12 meses antes (Figura 2) a raíz de un cuadro de infección respiratoria alta, que no mostraba alteraciones.

La tomografía computarizada (TC) de tórax, realizada 4 días después para mejor caracterización del hallazgo, confirmó la presencia de un nódulo periférico único en el segmento anterior del lóbulo superior derecho, de densidad homogénea, que no presentaba impregnación con el uso de contraste endovenoso (Figura 3) y que se

\footnotetext{
* Becada Radiología Pediátrica, Universidad de Chile, Clínica Las Condes. Santiago, Chile.

** Radióloga Tóraco-abdominal Adultos, Clínica Las Condes.

*** Pediatra, Clínica Las Condes.

**** Cirujano de Tórax, Clínica Las Condes.
} 
asociaba a leve engrosamiento de la pleura adyacente, sin evidencias de destrucción ósea.

Dado que la morfología del nódulo orientaba como primera posibilidad a una etiología inflamatorio-infecciosa, la paciente fue exhaustivamente reinterrogada respecto a sus hábitos, mascotas y viajes, surgiendo entonces el antecedente de un viaje hace 6 meses a la selva ecuatoriana, donde había realizado múltiples deportes acuáticos. Las posibilidades diagnósticas orientaban así a una etiología inflamatorio-infecciosa como primera posibilidad -fundamentalmente tuberculosis; mucho menos probable una causa neoplásica.

Los exámenes de laboratorio realizados (hemograma, perfil bioquímico) arrojaron resultados normales, así también como los cultivos

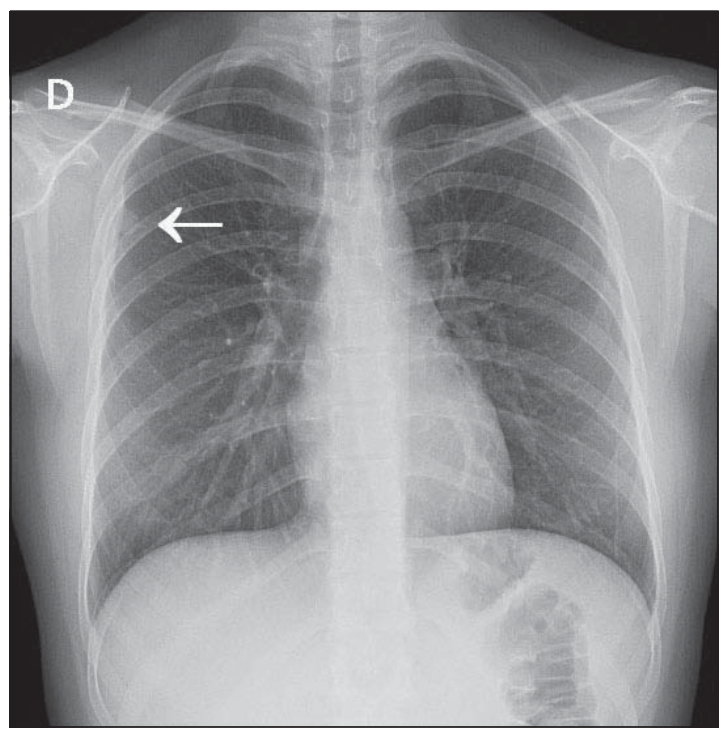

Figura 1. Rx de tórax proyección PA, muestra opacidad nodular marginal derecha (flecha).

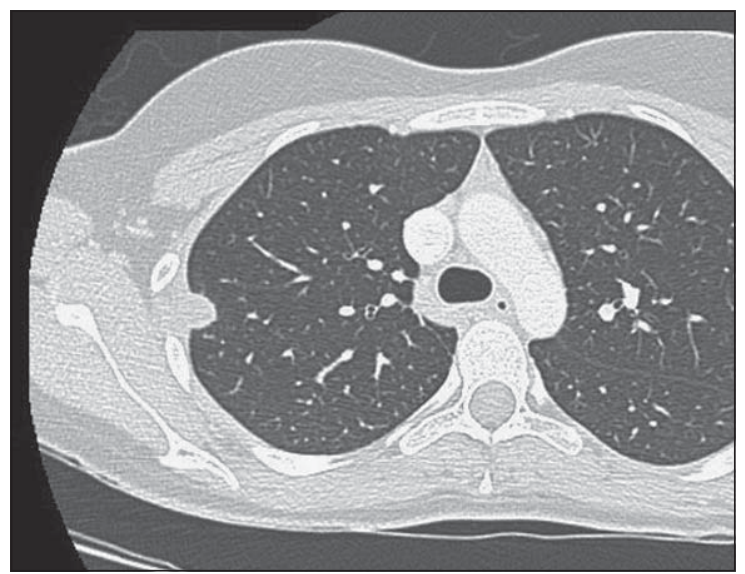

Figura 3. Corte axial de TC de tórax a nivel del tronco de la arteria pulmonar en ventana pulmonar (A) y de partes blandas (B), donde se visualiza a nivel del segmento anterior del lóbulo superior derecho una opacidad nodular homogénea de base pleural sin evidencia de calcificaciones. de expectoración (corriente, anaerobio, Koch y levaduras), la baciloscopía y la PCR sanguínea para citomegalovirus y adenovirus.

La paciente fue sometida a una resección segmentaria anterior del lóbulo superior derecho vía toracoscópica una semana después, encontrándose un nódulo pulmonar de base pleural unido a la pared a través de adherencias laxas. La biopsia rápida informó un nódulo de aspecto granulomatoso, lo que fue confirmado posteriormente con el hallazgo de hifas de Histoplasma capsulatum en la pieza operatoria.

La paciente evolucionó satisfactoriamente tras la cirugía y recibió tratamiento antimicótico con itraconazol por 1 mes, después de lo cual no ha vuelto a presentar síntomas.

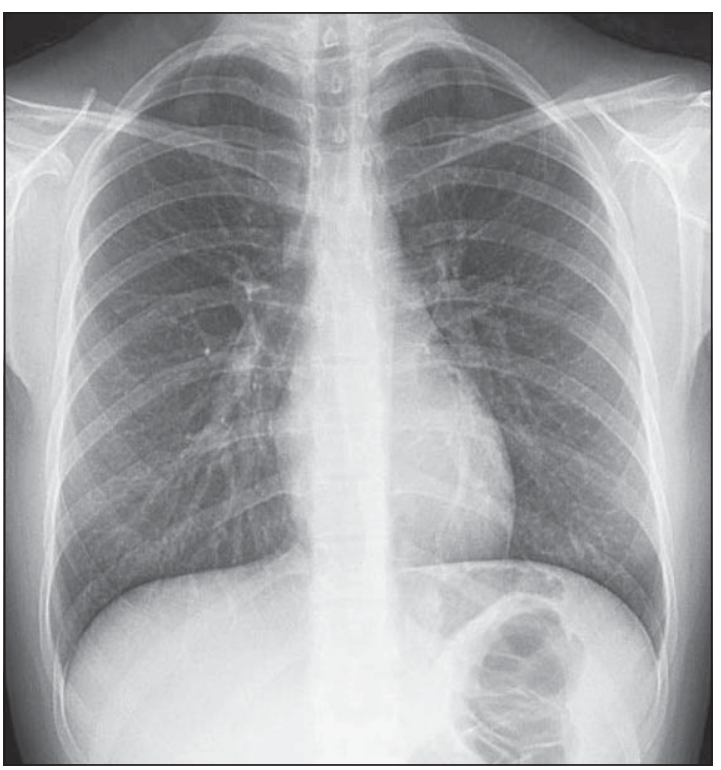

Figura 2. Rx de tórax obtenida 1 año antes no evidencia lesión.

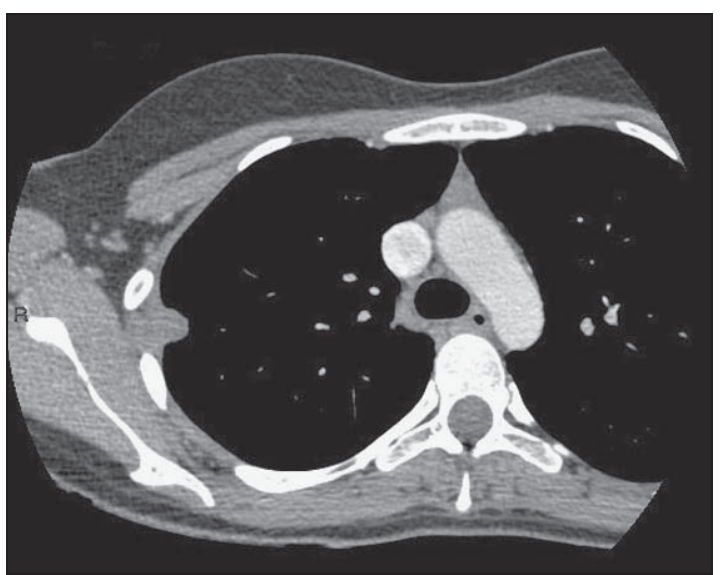




\section{Discusión}

Las infecciones pulmonares por hongos de distribución geográfica se ven esporádicamente en nuestro medio, debido a las desfavorables condiciones climáticas para su desarrollo y al efecto protector que ejercen las barreras naturales de nuestro país. A pesar de este relativo aislamiento geográfico, el aumento en el número de chilenos que viajan al exterior, y de los ciudadanos extranjeros que pasan temporadas largas en nuestro país ha conducido a un progresivo aumento de las patologías importadas ${ }^{1}$.

La histoplasmosis ha sido descrita únicamente en casos de personas que han viajado a zonas endémicas, correspondiendo sin embargo, a la micosis geográfica más frecuente. El hongo reside en la tierra, donde su presencia se ve favorecida por la existencia de deposiciones de pájaros y murciélagos, por lo que los gallineros y cuevas son sus sitios predilectos. La infección en seres humanos se adquiere por la inhalación de un alto inóculo de esporas, las que tras un período de incubación variable que va entre los 7 y los 21 días, pueden cursar una infección pulmonar o diseminada en el $10 \%$ de los casos, manteniéndose el cuadro asintomático en el $90 \%$ restante. Otras puertas de entrada descritas incluyen la piel y el tracto gastrointestinal ${ }^{1}$.

La clínica es altamente variable, al igual que los hallazgos imagenológicos, incluyendo desde casos asintomáticos (95\%), signos de neumopatía aguda, o síntomas asociados a compresión de estructuras mediastínicas. La mayor parte de los casos asintomáticos son pesquisados en forma incidental, identificando nódulos pulmonares solitarios de tamaño variable muchas veces calcificados, que frecuentemente están asociados a la presencia de adenopatías hiliares calcificadas y calcificaciones esplénicas. En los casos que debutan con infección pulmonar sintomática, el hallazgo más frecuente es una consolidación focal que no se resuelve con el tratamiento antibiótico habitual de una neumonia. Presentaciones más infrecuentes incluyen un patrón micronodular difuso similar a la tuberculosis miliar, en casos de infección hematógena diseminada, y las complicaciones, que consisten en granulomas mediastínicos, mediastinitis fibrosante, pericarditis y broncolitiasis ${ }^{2,3}$. En la fase exudativa de la enfermedad, las lesiones son mucho menos obvias que en la secuelar, en la que se pesquisan con facilidad múltiples focos cálcicos pequeños diseminados en ambos campos pulmonares y frecuentemente también a nivel del bazo ${ }^{4}$.

En el diagnóstico de la infección aguda se puede utilizar reacciones cutáneas, serología, detección de antígenos en sangre y orina, visión directa del agente en muestras clínicas y cultivo; el diagnóstico de elección es el antígeno urina$\mathrm{rio}^{6}$. El tratamiento incluye itraconazol o anfotericina por un período de 2 a 6 semanas. Aquellos casos que evolucionan hacia la cronicidad o con respuesta clínica arrastrada, deben recibir cursos más prolongados de antimicóticos, que pueden llegar a prolongarse hasta un año ${ }^{1}$. El uso de corticosteroides por plazos variables es una alternativa para obtener una respuesta más rápida, pudiendo ser útil frente a la sospecha de fibrosis pulmonar secundaria. La cirugía en general se reserva para resolución de complicaciones como mediastinitis fibrosante y fibrosis pulmonar, reservándose la biopsia pulmonar para aquellos casos en que hay dificultad para obtener un diagnóstico de certeza ${ }^{1}$.

\section{Referencias bibliográficas}

1.- CABELLO H, MANIEU D, NORIEGA M, MENESES M, PERALTA M, LARRAGUIBEL C. Histoplasmosis pulmonar. Rev Chil Infectol 2002; 19: 54-9.

2.- KIRCHNER S, HERNANZ-SCHULMAN M, STEIN S, WRIGHT P, HELLER R. Imaging of pediatric mediastinal histoplasmosis. Radio Graphics 1991; 11: 365-81.

3.- ROSSI S, MC ADAMS H, ROSADO DE CHRISTENSEN M, FRANKS T, GALVIN J. From the archives of the AFIP: Fibrosing mediastinitis. Radio Graphics 2001; 21: 737-57.

4.- MOËNNE K, ORTEGA X. Diagnóstico por imágenes del tórax pediátrico. $2^{\text {da }}$ Edición, Editorial Journal, Buenos Aires, 2012, 116-8.

5.- ODDO D, CHUAQUI B, CUBILLOS L. Histoplasmosis diseminada con examen ultraestructural del hongo. Rev Med Chile 1983; 111: 705-8.

6.- WHEAT J. Histoplasmosis: Experience during an outbreak in Indianapolis and review of the literature. Medicine (Baltimore) 1997; 76: 339-54.

Correspondencia a:

Dra. Manuela Pérez M.

Radiología Pediátrica

Clínica Las Condes, Santiago, Chile.

E-mail: maneperez@yahoo.com 